\title{
Approaches in Diagnosis and Treatment of Patients with Idiopathic Pulmonary Fibrosis: A Questionnaire Study
}

\section{Ceyda Anar ${ }^{1}$, Oğuzhan Okutan², Oğuz Uzun³, Savaş Özsu, Bülent Altınsoy ${ }^{5}$}

${ }^{1}$ Clinic of Chest Diseases, Dr. Suat Seren Chest Diseases and Thoracic Surgery Training and Research Hospital, İzmir ${ }^{2}$ Clinic of Chest Diseases, Gülhane Military Medical Academy Haydarpaşa Training Hospital, İstanbul ${ }^{3}$ Department of Chest Diseases, Ondokuz Mayıs University Faculty of Medicine, Samsun ${ }^{4}$ Department of Chest Diseases, Karadeniz Technical University Faculty of Medicine, Trabzon ${ }^{5}$ Department of Chest Diseases, Bülent Ecevit University Faculty of Medicine, Zonguldak

\begin{abstract}
Objective: As Turkish Respiratory Society Diffuse Parenchymal Lung Diseases-Pulmonary Vascular Diseases Study Group (TRS DPLD-PVD SG), we aimed to demonstrate the approaches of physicians with a questionnaire toward the patients with IPF in our country.

Methods: An invitation letter including a questionnaire with 24 questions to assess the approaches they prefer in the patients with IPF and the capabilities of the departments they work at and a link for the questionnaire was directed to the mail groups of chest diseases and thoracic surgery specialists. Responses of the physicians who participated in the questionnaire were reviewed.

Results: Thirty percent of the participants saw less than 5 patients with IPF in a year and $16.8 \%$ of them saw more than $21.66 .3 \%$ of participants stated that anamnesis, symptoms and clinical findings along with typical radiologic findings would be sufficient for the diagnosis, while $27.7 \%$ suggested that pathological findings should indicate IPF along with clinic and radiologic ones. When the methods used for tissue sampling were viewed; application rates of bronchoscopic transbronchial biopsy, thoracoscopic biopsy and open lung biopsy were found very close to one another.In the patients with the suspected disease of IPF, the fields in which the hesitation was the most problematic were respectively pathological examination of biopsies (73.2\%) and interpretation of radiologic findings (49.5\%). $37.6 \%$ of the patients with diagnosis of IPF were directed to experienced centers; medical treatment and drugless follow-up rates were respectively $33.6 \%$ and $14.8 \%$. Among the participants, $29.7 \%$ suggested lung transplantation for all cases while $48.5 \%$ only preferred this operation in particular ones.
\end{abstract}

Conclusion: Some of the results of our study is compatible with the guidelines of IPF, is to show that the quality of debate and confusion still continued in this regard.

Keywords: Diagnosis, idiopathic pulmonary fibrosis, treatment

Received Date: 20.12 .2014 Accepted Date: 30.04 .2015 Available Online Date: 04.06 .2015

This study has been orally presented in the $36^{\text {th }}$ National Congress of Turkish Respiratory Society (Çeşme, İzmir, 15-19 October, 2014).

Address for correspondence Ceyda Anar

E-mail: drceydaanar@hotmail.com

This work is licensed under a Creative 4.0 International License

DOI: $10.5152 /$ ejp.2015.73792

-Available online at www.eurasianjpulmonol.com

\section{INTRODUCTION}

Idiopathic pulmonary fibrosis (IPF) is a prototype of chronic, progressive, and diffuse parenchymal pulmonary diseases that can be an important cause of mortality and morbidity. It is a form of chronic interstitial pneumonia that occurs with progressive fibrosis and has an unknown etiology. The clinical picture of IPF is histopathologically and radiologically consistent with usual interstitial pneumonia (UIP) that occurs at advanced ages ( $>50$ years) and is limited to the lung $(1,2)$. The final diagnosis is established by ruling out other possible factors and by demonstrating UIP pattern. In lung biopsies, UIP pattern can also be seen in some cases such as collagen tissue diseases, progressed fibrosis phases of hypersensitivity pneumonitis, asbestosis, and drug toxicity (3). Because the appearance of UIP pattern in lung biopsies is alone insufficient for establishing the diagnosis of IPF and some difficulties are encountered during differentiation from other interstitial pneumonias, a multidisciplinary approach with a specialist in chest diseases, pathology, and radiology is used for the diagnosis of IPF at present. Because of the difficulties in diagnosis and the absence of a common clinical approach in the treatment and follow-up of the disease, the American Thoracic Society (ATS) and European Respiratory Society (ERS) published a common consensus report for IPF in 2000, and this report was updated in $2011(1,4)$. Thus, clinical, radiological, and pathological data were described, particularly by increasing the use of high-resolution computed tomography (HRCT) and restricting the routine implementation of lung biopsy (4). Moreover, in the last 10 years, a remarkable progression has been achieved in the definition of clinical, radiological, and histopathological IPF findings, and a general worldwide standardization and algorithm have been developed for the diagnosis of the disease.

Worldwide, different approaches have been seen in the diagnosis and treatment of IPF patients among physicians in Turkey. As the Turkish Respiratory Society Diffuse Parenchymal Lung Diseases-Pulmo- 
nary Vascular Diseases Study Group (TRS DPLD-PVD SG), we aimed to demonstrate the diagnostic and treatment approaches of specialists in chest diseases to IPF patients and the facilities that could provide a multidisciplinary approach to this disease at their institutions through a questionnaire.

\section{METHODS}

The link for a web-based questionnaire consisting of 24 questions was sent to the personal e-mail addresses of specialists in chest diseases and thoracic surgery who were selected as the target population. In this manner, participants were prevented from responding to the questionnaire more than one time. Furthermore, via e-mail groups of the societies, the same physician population was invited to participate in the questionnaire study up to four times at 1-month intervals beginning from April 2014.

Specialist physicians in the related branches were requested to answer the questionnaire by displaying their own attitudes and behaviors. Participants' personal information, such as name, surname, title, and institution were not asked, except their areas of specialization, duration of working as a specialist physician, and type of their institutions (such as university, education hospital, and state hospital).

In addition to these initial questions regarding the features of the participants, there were other questions regarding whether laboratory examinations for rheumatic diseases were performed at their institutions, the presence of a rheumatologist and pathologist studying the respiratory system, the number of IPF patients encountered in a year, the most frequently hesitated areas during diagnosis, treatment, and follow-up.

For some questions, the participants were requested to provide only one answer, but for some questions, the participants were allowed to provide more than one answer.

The questions included in the questionnaire are provided in Table 1.

\section{Statistical Analysis}

For the evaluation of the responses provided to the questionnaire in the study, number and percentage (\%) were used; for the evaluation of multiple responses (in case of more than one answer), number of responses and percentage from descriptive statistics were used. The percentage values that were obtained were summarized using bar graphs and pie charts. Crosstab was used to examine the distribution of opportunities and specialists in the institutions where physicians worked. The data obtained in the study were entered in a database created in the SPSS for Windows, Version 16.0 [Statistical Package for the Social Sciences Inc. (Released 2007), Chicago, IL, USA], software, and statistical analyses of the data were performed using the same statistical program.

\section{RESULTS}

A total of 101 specialist physicians from the departments of chest diseases $(n=93)$ and thoracic surgery $(n=8)$ answered the questionnaire. Of the physicians, $47.5 \%$ worked in universities, $22.7 \%$ in education and research hospitals, $11.8 \%$ in state hospitals, $8.9 \%$ in private hospitals, $2.9 \%$ in foundation hospitals, and $5.9 \%$ in other hospitals.

It was found that all rheumatic laboratory examinations, which contributed to the diagnosis, were performed at the institutions of $54.6 \%$ of the participants who answered the questionnaire. Although some of these examinations were performed at the institutions of $34.6 \%$ of
Table 1. Questions included in the questionnaire

Question 1: Your age (year of birth)?

Question 2: Your occupation?

Question 3: Your area of specialization?

Question 4: Duration of working in the area of chest diseases?

Question 5: Your institution?

Question 6: Is there a rheumatologist in your hospital?

Question 7: Where is your hospital (city)?

Question 8: Is it possible to perform laboratory examinations for rheumatoid diseases in your hospital?

Question 9: Is there a pathologist specialized on the respiratory system in your hospital?

Question 10: How many patients with IPF have you examined in a year?

Question 11: Which of following data are enough according to you for establishing the diagnosis of IPF?

Question 12: If you want to take tissue sample for IPF diagnosis, which of the following options would you prefer?

Bronchoscopic transbronchial biopsy, thoracoscopic biopsy, open lung biopsy, I do not perform biopsy and I try to diagnose according to clinical and laboratory findings

${ }^{*}$ Question 13: During the diagnosis stage of a patient suspected of having IPF, which areas do you mostly hesitate in?

Interpretation of biochemical examination results, radiological findings, functional measurement values, and pathological evaluation of biopsies (bronchoscopic or surgical)

Question 14: Are meetings for evaluating and discussing the patients suspected of having IPF held in your hospital?

Question 15: Which of the following options do you prefer for patient diagnosed with IPF?

I direct the patient to a center experienced in this issue, I recommend medical therapy for IPF, I follow up without any medication, other.

Question 16: If you have to recommend medical therapy to your patients, which one would you recommend?

Corticosteroid, corticosteroid + two immunosuppressive agents (azathioprine, cyclophosphamide, or methotrexate), $\mathrm{N}$ - acetylcysteine, corticosteroid + two immunosuppressive agents (azathioprine, cyclophosphamide, or methotrexate) $+\mathrm{N}$-acetylcysteine, pirfenidone, I follow up without medication

Question 17: If you follow up your patients diagnosed with IPF, how often do you control them?

${ }^{*}$ Question 18: Which of following examinations do you order for the control of patients?

Spirometry, DLCO, 6-min walk test, chest radiography, HRCT, echocardiography, cardiopulmonary exercise test, symptom and/or life quality questionnaires, blood analysis

Question 19: Do you recommend influenza vaccine for patients with IPF?

Question 20: Do you recommend pneumococcal vaccine for patients with IPF?

Question 21: Do you direct your IPF patients to pulmonary rehabilitation program?

Question 22: Is lung transplantation performed at your hospital?

Question 23: Do you recommend lung transplantation to IPF patients?

Question 24: When would you recommend transplantation to patient diagnosed with IPF?

When I diagnose, I give medical therapy; if patient's health deteriorates, I direct to the unit performing transplantation; I recommend according to functional measurements and radiological findings; others.

*Participants may choose more than one answer for these questions. IPF: Idiopathic pulmonary fibrosis 
the participants, none of these examinations were performed at the institution of $8.9 \%$ of the participants. The rate for the presence of a pathologist specialized in rheumatology and the respiratory system was found to be $49.5 \%$ and $37.6 \%$, respectively (Table 2 ).

Of the participants, 30.6\% examined less than five IPF patients in a year and $16.8 \%$ examined more than 21 IPF patients in a year (Figure 1).

Of the participants, $66.3 \%$ stated that the presence of anamnesis, symptom, and clinical findings with typical radiological findings may be enough for the diagnosis of IPF, but $27.7 \%$ specified that histopathological findings must also be consistent with IPF as well as with clinical and radiological findings. In the evaluation of techniques used for taking tissue sample for the diagnosis of IPF, it was observed that the rates of preference for transbronchial, thoracoscopic, and open lung biopsy were approximately similar $(25.7 \%, 24.7 \%$, and $25.7 \%$, respectively). Among the hesitated points during diagnosis in patients suspected of having IPF, problems related to the pathological evaluation of biopsies were mostly encountered at the rate of $73.2 \%$. This was followed by the interpretation of radiological findings at the rate of $49.5 \%$ (Table 3 ).
It was learned that case meetings for evaluating the patients with a suspicion of IPF were always conducted and occasionally conducted at the rate of $28.7 \%$, respectively, and never conducted at the rate of $42.5 \%$ at the place where the physicians participating in the questionnaire work.

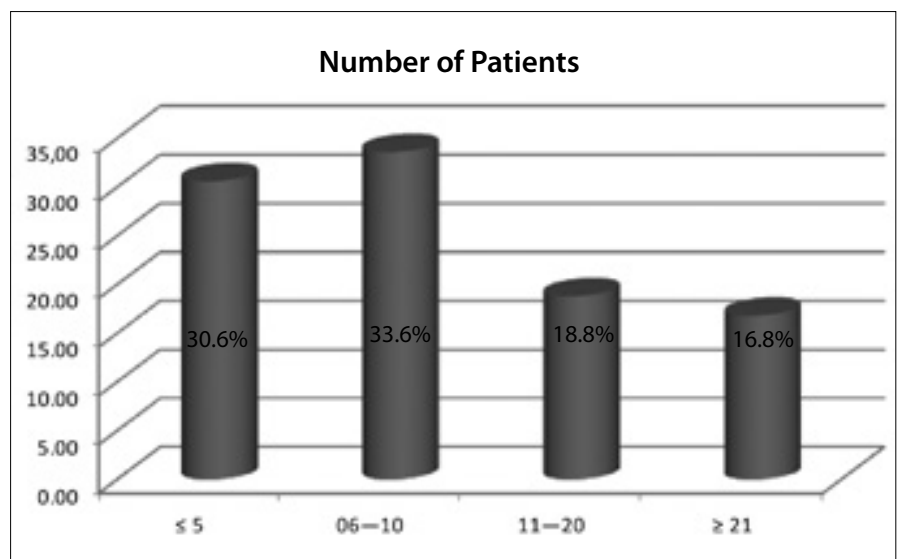

Figure 1.The number of patients examined by physicians in a year

Table 2. The state of opportunities and specialists in the institutions of the physicians participating in the questionnaire study

\begin{tabular}{|c|c|c|c|c|c|c|}
\hline & \multicolumn{2}{|c|}{ Yes } & \multicolumn{2}{|c|}{ No } & \multicolumn{2}{|c|}{ Partially } \\
\hline Number of rheumatologists in the hospital in which you work & 50 & 49.5 & 51 & 50.5 & & \\
\hline Laboratory examinations for rheumatoid diseases & 57 & 56.4 & 9 & 8.9 & 35 & 34.6 \\
\hline Number of pathologists specialized in the respiratory system & 38 & 37.6 & 63 & 62.3 & & \\
\hline
\end{tabular}

Table 3. The techniques used for IPF diagnosis by participants and their hesitations

\begin{tabular}{|c|c|c|}
\hline Options & n & $\%$ \\
\hline \multicolumn{3}{|l|}{ For you, which of following data are enough for establishing the diagnosis of IPF? } \\
\hline Anamnesis, symptoms, and clinical findings & 1 & 0.9 \\
\hline Typical radiological findings & 3 & 2.9 \\
\hline The data given in $a$ and $b$ are sufficient if they support the diagnosis & 67 & 66.3 \\
\hline \multicolumn{3}{|l|}{ If you want to take tissue sample for IPF diagnosis, which one do you prefer? } \\
\hline Bronchoscopic transbronchial biopsy & 26 & 25.7 \\
\hline Thoracoscopic biopsy & 23 & 24.7 \\
\hline Open lung biopsy & 25 & 22.7 \\
\hline \multicolumn{3}{|l|}{ During the diagnosis stage of a patient suspected of having IPF, which area(s) do you mostly hesitate in? } \\
\hline Interpretation of biochemical examination results & 7 & 6.9 \\
\hline Interpretation radiological findings & 50 & 49.5 \\
\hline Interpretation functional measurement values & 8 & 7.9 \\
\hline Pathological evaluation of biopsies taken & 74 & 73.2 \\
\hline
\end{tabular}


Table 4. The approaches of the participants to treatment and follow-up of IPF

Questions
The patient diagnosed with IPF
I direct to a center experienced in this issue
I recommend medical therapy for IPF
I follow up without any medication
Other
As medical therapy to IPF patients
Corticosteroid
Corticosteroid + two immunosuppressive agents
(azathioprine, cyclophosphamide, or methotrexate)
N-acetylcysteine
Corticosteroid + two immunosuppressive
agents (azathioprine, cyclophosphamide, or
methotrexate) + N-acetylcysteine
Pirfenidone
I follow up without medication
Other
$\%$

\begin{tabular}{|c|c|}
\hline $\mathbf{n}$ & $\%$ \\
\hline 38 & 37.6 \\
\hline 34 & 33.6 \\
15 & 14.8 \\
\hline 14 & 13.8 \\
\hline
\end{tabular}

How often do you control your IPF patients?

Every 3 months

Every 6 months

Every 12 months

Which of following examinations do you order for the control of patients?

\begin{tabular}{|l|c|c|} 
Spirometry & 90 & 89.1 \\
DLCO & 63 & 62.3 \\
6-min walk test & 53 & 52.4 \\
Chest radiography & 78 & 77.2 \\
HRCT & 51 & 50.5 \\
Echocardiography & 38 & 37.6 \\
Cardiopulmonary exercise test & 4 & 3.9 \\
Symptom and/or life quality questionnaires & 39 & 38.6 \\
Blood analysis & 31 & 30.6 \\
Other & 1 & 0.9 \\
DLCO: diffusing capacity of the lungs for carbon monoxide, IPF: idiopathic \\
pulmonary fibrosis, HRCT: high-resolution computed tomography \\
\hline
\end{tabular}

Table 5. The views of the participants for vaccine, rehabilitation and transplantation in IPF patients

\begin{tabular}{|l|c|c|c|c|c|c|}
\hline \multirow{2}{*}{ Suggestions } & \multicolumn{2}{|c|}{ Yes } & \multicolumn{2}{c|}{ Partially } & \multicolumn{2}{c|}{ No } \\
\hline Influenza vaccine & $\mathbf{n}$ & $\%$ & $\mathbf{n}$ & $\%$ & $\mathbf{n}$ & $\%$ \\
\hline Pneumococcal vaccine & 70 & 79.2 & 20 & 19.8 & 1 & 0.9 \\
Rehabilitation & 51 & 78.2 & 21 & 20.7 & 1 & 0.9 \\
\hline Transplantation & 30 & 29.7 & 49 & 48.5 & 22 & 21.7 \\
\hline
\end{tabular}

It was confirmed that $37.6 \%$ of the patients diagnosed with IPF were referred to experienced centers. The rates of medical treatment and follow-up without any medication were found to be $33.6 \%$ and $14.8 \%$, respectively. Of the physicians, $87.1 \%$ followed up patients every 3 months, and the mostly preferred examination during follow-up control was spirometry (89.1\%) (Table 4).

It was revealed that $50.5 \%$ of the participants always suggested and $18.8 \%$ sometimes suggested rehabilitation to their patients. On the other hand, $30.6 \%$ stated that they never suggested rehabilitation. While approximately $80 \%$ of the participants recommended both influenza and pneumococcal vaccine, $29.7 \%$ always and $48.5 \%$ sometimes recommended lung transplantation (Table 5).

It was found that lung transplantation was not performed at the rate of $89.1 \%$ in their hospitals. While the rate of the physicians who decided on transplantation according to the functional test results and radiological findings was $43.5 \%, 35.6 \%$ of the physicians decided on transplantation when the diagnosis of IPF was established and $11.8 \%$ decided on transplantation in case of deterioration despite medical treatment (Figure 2).

\section{DISCUSSION}

The approaches for the diagnosis and treatment of IPF have been developing every day. However, multidisciplinary approach maintains its importance, particularly in diagnosis. For this, it is significant that the physician should have sufficient opportunities for the evaluation of the patients who are suspected of having IPF.

In this questionnaire study, we aimed to reveal the approaches of the physicians to the diagnosis and treatment of IPF patients in our country, their general tendencies, and the opportunities that their work places had. Based on the evaluation of data obtained from the questionnaire items, differences among participants were observed in the stages of diagnosis and treatment with regard to the approaches to IPF.

Since the diagnosis is difficult and the incidence of disease is low, it is difficult to conduct an epidemiological study on this disease group; therefore, the number of studies on the epidemiological features of this disease is limited in the literature. In the study conducted by Musellim et al. (5), in which they evaluated 2245 patients with diffuse parenchymal pulmonary disease, it was detected that $19.9 \%$ of the patients were diagnosed with IPF. While the prevalence has been

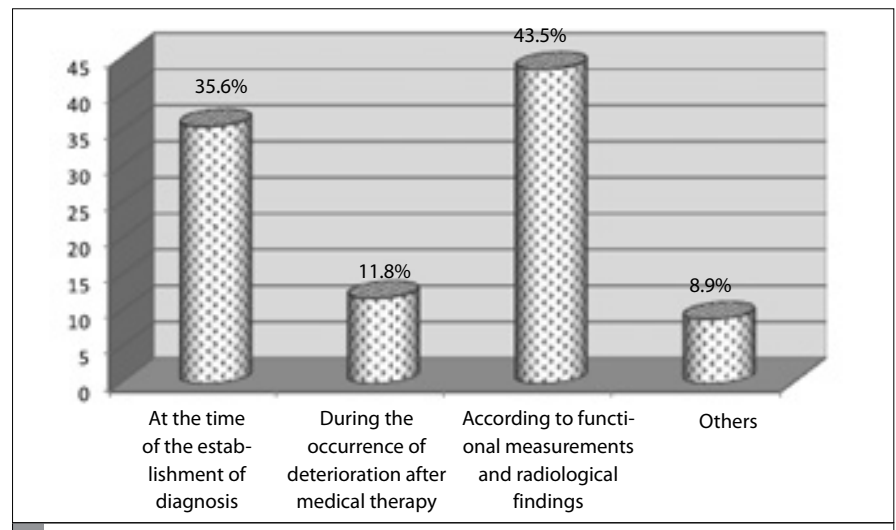

Figure 2. The time distribution of the participants' recommendation for transplantation 
found to be between 14 and 63 per 100,000 people in the USA, it is between 14 and 28 per 100,000 people in Europe. On the other hand, the incidence rate is $6.8-17.4$ per 100,000 people in the USA and 4.6-8.8 per 100,000 people in Europe (6).

In our study, $30.6 \%$ of the participants stated that they examined less than five IPF patients in a year, and $16.8 \%$ of the participants examined more than 21 IPF patients in a year. The primary examination technique in the algorithm of IPF diagnosis is HRCT. In HRCT, the UIP pattern is characterized by the presence of reticular opacities, which are basal and peripheral with subpleural localization, and HRCT is often associated with traction bronchiectasis and the appearance of honeycomb (4).

In patients suspected of having IPF, chest radiography is less useful than HRCT. In some studies, the positive predictive value of HRCT was reported to be $90 \%-100 \%$ for the diagnosis of $\operatorname{UIP}(7,8)$. In the guideline of ATS/ERS/JRS/ALAT, it is suggested that surgical lung biopsy is not required anymore because a good quality HRCT has a high specificity for the detection of histopathological pattern of UIP. While the presence of consistent clinical findings and radiological UIP pattern is accepted to be sufficient for the diagnosis of a patient with idiopathic interstitial pulmonary disease, surgical biopsy is recommended in the presence of inconsistent clinical-radiological findings or atypical features of HRCT (4). In our study, $66.3 \%$ of the participants stated that the presence of anamnesis, symptoms, and clinical findings with typical radiological findings may be sufficient for IPF diagnosis and $27.7 \%$ of the participants specified that pathological findings must be consistent with IPF as well as clinical and radiological findings. The accuracy of IPF diagnosis increases with clinical, histopathological, and radiological correlation, and this is possible with a multidisciplinary debate among physicians who are experienced in interstitial pulmonary diseases. However, it should be kept in mind that HRCT or pathological UIP pattern is not $100 \%$ specific for IPF (9). Inconsistent histopathological patterns have been reported in surgical lung biopsies taken from different segments. It is specified that the course of the disease is similar to UIP pattern in all lobes in patients who have both UIP pattern and fibrotic non-specific interstitial pneumonia (NSIP) pattern $(10,11)$. With appropriate radiology and elimination of other causes, the diagnosis of IPF can be made; however, existent knowledge indicates that surgical lung biopsy must be taken from more than one lung lobe in patients for whom radiology is not suitable, in other words, those who are suspected of having IPF. In studies comparing open thoracotomy with VATS, the diagnostic success was found to be similar. No adequate data are available on specificity and positive predictive values of transbronchial biopsy as a tissue sample in IPF. Moreover, the number and place of transbronchial biopsy are unknown. Transbronchial lung biopsy (TBLB) can be useful only for ruling out some diseases, such as granulomatous diseases or sarcoidosis, rather than for diagnoses (12). In contrast, considering the techniques used for taking tissue sample for the diagnosis of IPF in our study, it was observed that the rates of transbronchial biopsy, thoracoscopic, and open lung biopsies were approximately similar (25.7\%, 24.7\%, and 25.7\%, respectively). In a case series by Arbak et al. (13) that included 12 IPF patients, it was found that the diagnosis of one patient (8.3\%) was made via open lung biopsy; it was also found that for 3 of 5 patients (41.7\%) who underwent TBLB, biopsy material provided diagnostic contribution. In a study conducted in England, TBLB procedure was used at the rate of $33 \%$ and open lung biopsy was utilized at the rate of $7.5 \%$ as a diagnostic approach (14).
In recent years, after morphological findings of IPF have become well known via open lung biopsies by pathologists, some studies have reported that the diagnosis of IPF can be predicted with bronchoscopic biopsy in the presence of patchy appearance, fibroblastic focuses, and honeycomb appearance as well as with an adequate size of transbronchial biopsy (15).

In our study, the rate for the presence of pathologists specialized on the respiratory system at the place of work of the physicians was $37.6 \%$. The mostly hesitated point in the diagnostic stage of the patients who were suspected of having IPF was related to the pathological evaluation of biopsies at the rate of $73.2 \%$. As it has been previously known that from the view of a pathologist, the most important and basic histopathological criterion for diagnosis is a heterogeneous appearance in which fibrosis is observed with scars and honeycomb changes in the less affected or normal parenchyma. In some biopsies, fibrosis pattern that does not completely form UIP pattern can be detected. These biopsies are defined as non-classified fibrosis. In the absence of histopathological features consistent with an alternative disease, such as hypersensitivity pneumonitis and sarcoidosis, these biopsies can be evaluated as IPF if consistent clinical and radiological findings exist. This shows that a multidisciplinary approach (specialist in chest diseases, radiologist, and pathologist) is very important for establishing the correct diagnosis. It was found that at the place of work of the participants, meetings for discussing and evaluating the patients suspected of having IPF were always and sometimes held at the rate of $28.7 \%$, respectively. On the other hand, they were never held at $42.5 \%$ of the institutions. In the guideline, it is recommended to refer the patients to an experienced center if it is impossible to hold a multidisciplinary discussion (4).

The UIP pattern can be histopathologically seen in connective tissue disease, and interstitial pulmonary disease can be the only finding in case of connective tissue disease (16). Therefore, it has been suggested that serological examination must be performed for the differential diagnosis of connective tissue disease in most of the patients (4). Moreover, in the absence of the symptoms and findings of connective tissue disease, the presence of RF, anti-CCP, ANA titer, and pattern must be investigated. In our study, rheumatic laboratory examinations could be performed at the place of work of $56.4 \%$ of the physicians, and the rate of the presence of rheumatologists at the same institutions was $49.5 \%$. This shows us that examinations for the differential diagnosis of underlying rheumatic diseases cannot be performed at every health center, and that it may be necessary to refer these patients to another hospital.

Despite many studies conducted in the last decade, a treatment regimen that will change the poor course of the disease has not been developed for IPF patients. In Cochrane analysis evaluating the efficiency of corticosteroids in IPF and published in 2003, no high-quality study was found and there was only one non-randomized retrospective study. This review demonstrated that there was no sufficient evidence for supporting the use of corticosteroids in IPF (17). Furthermore, in large-scale retrospective studies, any advantage for survival could not be shown in IPF patients using corticosteroids (18-20). Contrary to the 2000 Guideline, azathioprine and cyclophosphamide therapies as well as corticosteroid therapy were not recommended in the 2011 Guideline (4). In accordance with all these studies, it was revealed in our study that $21.7 \%$ of the participants recommended corticosteroid, $19.8 \%$ recommended corticosteroid + two immuno- 
suppressive therapy (azathioprine, cyclophosphamide, or methotrexate) $+\mathrm{N}$-acetylcysteine, and $7.9 \%$ recommended corticosteroid + two immunosuppressive therapy in the treatment of the patients diagnosed with IPF. On the other hand, $11.8 \%$ of the participants mentioned that they followed up without administering a medical therapy. In the PANTHER study published in 2012, mortality and hospitalization rates were found to be higher in patients receiving triple therapies than in the placebo group (21).

The use of pirfenidone, which can be orally consumed and the anti-inflammatory, antioxidant, and antifibrotic features of which were demonstrated both in vitro and in vivo, was approved for IPF treatment in some countries (Europe, USA, and Japan), except our country. In our study, it was detected that $9.9 \%$ of the participants used pirfenidone in IPF treatment.

It is important to define the progressive disease efficiently in IPF patients and to treat symptoms in a timely manner before deterioration, oxygenation, and complications during the course of the disease. Moreover, for obtaining the best functional capacity beginning from the establishment of diagnosis, pulmonary rehabilitation (PR) programs should be put into use before the development of end-stage lung disease and of apparent ventilatory limitation and pulmonary hypertension $(4,22)$. In our study, $50.5 \%$ of the participants always and $30.5 \%$ sometimes directed their patients to PR, but $18.8 \%$ never directed their patients to PR. Furthermore, $87.1 \%$ of the participants controlled their patients almost every 3 months, and the most frequently preferred examination technique during follow-up was spirometry, which can easily be implemented everywhere and showed functional evaluation beginning from the diagnostic stage (89.1\%). In addition to respiratory function test, diffusing capacity of the lungs for carbon monoxide (62.3\%) and a 6-min walk test (52.8\%) for functional evaluation as well as HRCT (50.5\%) for radiological evaluation were required. In the 2011 Guideline, to efficiently define progressive disease in IPF patients and to treat complications on time, follow-ups at 3-6-month intervals are recommended (4). In addition, in our study, patients were followed up. With regard to the determination of disease severity, dynamic respiratory function tests display a lower correlation than the diffusing capacity of the lungs for carbon monoxide or exercise tests (23). Moreover, impaired respiratory function tests, despite the absence of deterioration in the symptoms of IPF patients, demonstrates non-response to treatment; these patients must be evaluated for lung transplantation (24). IPF is a disease necessitating functional evaluation at the beginning of the diagnostic stage. The most helpful procedures during the determination of prognosis and assessment of the response to treatment are spirometric examination as well as diffusing capacity and 6-min walk tests (22).

Despite the median survival indicated in previously conducted studies, the median survival of IPF in this study is between 2 and 5 years after the establishment of diagnosis (25). Therefore, since the increase in the number of studies in 2004, the evaluation of all treatment options has been attempted to get the advantage of survival $(26,27)$. In IPF, which is a disease with exacerbations, it has been reported that these exacerbations are independent of disease severity, age, and immunosuppressive treatment. However, only in one study, IPF has been reported to be associated with genetic susceptibility (28). According to the 2006 guideline of the International Society of Heart and Lung Transplantation (ISHLT), despite all treatment approaches and continual studies at present, the only treatment option providing long-term survival, particularly in patients with exacerbations is lung transplantation (29). Of the participants in our study, $29.7 \%$ always and $48.5 \%$ sometimes recommended lung transplantation to their patients. While the rate of the participants who decided on transplantation according to functional measurements and radiological findings was $43.5 \%$ in our study, the rate of the physicians deciding on lung transplantation at the time of IPF diagnoses and in the occurrence of deterioration despite medical therapy was 35.6\% and $11.8 \%$, respectively. Contrary to this, in the ISHLT 2006 guideline, the criteria for directing to lung transplantation are specified for the histological or radiological existence of UIP (regardless of vital capacity) and the presence of histologically proven NSIP. Furthermore, for early inclusion in the transplantation list, these patients should be directed to transplantation as soon as their diagnosis is established because the mortality rate is high among the patients included in the list for interstitial pulmonary diseases indicated with lung transplantation. However, the patients in this group have the highest survival rate after lung transplantation. It is notified to all chest diseases societies in the ISHLT 2006 guideline that patients must be directed to transplantation in the early period, and the most appropriate time for transplantation must be determined because of high mortality (29).

The most important limitation of our study is that the number of specialists in chest diseases and thoracic surgery who participated in the questionnaire was low.

\section{CONCLUSION}

Although some of the results obtained in our study are consistent with IPF guidelines, they also show that discussions and confusions regarding this issue are still ongoing. In the recent guidelines, a multidisciplinary approach is recommended for the diagnosis and treatment of IPF and immunosuppressive drugs, such as corticosteroid, azathioprine, and methotrexate, which have been previously used in treatment, are not suggested to be used in treatment any more. However, in our study, it has been seen that most of the participants still use these treatment protocols.

Therefore, we believe that the formation of a national guideline on IPF, which has a poor prognosis and does not have a medical cure by following studies on the disease, will facilitate the work of specialists in chest diseases during the diagnosis and treatment of IPF, which is increasing with time.

Ethics Committee Approval: Due to the survey design of the study, ethics committee approval was not taken.

Informed Consent: Due to the survey design of the study, informed consent was not taken.

Peer-review: Externally peer-reviewed.

Author Contributions: Concept - O.O., O.U., S.Ö., C.A., B.A.; Design O.O., O.U., S.Ö., C.A., B.A.; Supervision - O.O., O.U., S.Ö., C.A., B.A.; Resource - O.O., O.U., S.Ö., C.A., B.A.; Data Collection and/or Processing - O.O., O.U., S.Ö., C.A., B.A.; Analysis and/or Interpretation - O.O., O.U., S.Ö., C.A., B.A.; Literature Review - O.O., O.U., S.Ö., C.A., B.A.; Writer O.O., O.U., S.Ö., C.A., B.A.; Critical Review - O.O., O.U., S.Ö., C.A., B.A.

Conflict of Interest: No conflict of interest was declared by the authors.

Financial Disclosure: The authors declared that this study has received no financial support. 


\section{REFERENCES}

1. American Thoracic Society: Idiopathic pulmonary fibrozis: diagnosis and treatment. International consensus statement. American Thoracic Society (ATS), and the European Respiratory Society (ERS). Am J Respir Crit Care Med 2000; 161: 646-64. [CrossRef]

2. Travis WD, Costabel U, Hansell DM, King TE Jr, Lynch DA, Nicholson AG, et al. An official American Thoracic Society/European Respiratory Society statement: Update of the international multidisciplinary classification of the idiopathic interstitial pneumonias. Am J Respir Crit Care Med 2013; 188: 733-48. [CrossRef]

3. Smith M, Dalurzo M, Panse P, Parish J, Leslie K. Usual-interstitial pattern fibrosis in surgical lung biopsies. Clinical, radiological and histopathological clues to aetiology. J. Clin Pathol 2013; 66: 896-903. [CrossRef]

4. Raghu G, Collard HR, Egan JJ, Martinez FJ, Behr J, Brown KK, et al. An official ATS / ERS /JRS/ALAT statement: idiopathic pulmonary fibrosis: evidence-based guidelines for diagnosis and management. Am J Respir Crit Care Med 2011; 183: 788-824. [CrossRef]

5. Musellim B, Okumuş G, Uzaslan E, Akgün M, Cetinkaya E, Turan O, et al. Epidemiology and distribution of interstitial lung diseases in Turkey. Clin Respir J 2014; 8: 55-62. [CrossRef]

6. Fernández Pérez ER, Daniels CE, Schroeder DR, St Sauver J, Hartman TE, Batholmai BJ, et al. Incidence, prevalence, and clinical course of idiopathic pulmonary fibrosis: a population-based study. Chest 2010; 137: 129-37. [CrossRef]

7. Hunnighake GW, Zimmerman MB, Schwartz DA, King TE Jr, Lynch J, Hegele $\mathrm{R}$, et al. Utility of alung biopsy for the diagnosis of the idiopathic pulmonary fibrosis. Am J Respir Crit Care Med 2001; 164: 193-6. [CrossRef]

8. Grenier P, Valeyre D, Cluzel P, Brauner MW, Lenoir S, Chastang C. Chronic diffuse interstitial lung disease: diagnostic value of chest radiography and high resolution CT. Radiology 1991; 179: 123-32. [CrossRef]

9. Çiledağ A, Çelik G. İdyopatik Pulmoner Fibrozis güncel tanı ve tedavi yaklaşımları. In: Tanı, Zafer Kartaloğlu, Oğuzhan Okutan, editors, İstanbul 2013, pp.107-11.

10. Monaghan H, Wells AU, Colby TV, du Bois RM, Hansell DM, Nicholson AG. Prognostic implications of histologic patterns in multiple surgical lung biopsies from patients with idiopathic interstitial pneumonias. Chest 2004; 125: 522-6. [CrossRef]

11. Flaherty KR, Travis WD, Colby TV, Toews GB, Kazerooni EA, Gross BH, et al. Histopathologic variability in usual and nonspecific interstitial pneumonias. Am J Crit Care Med 2001; 164: 1722-7. [CrossRef]

12. Khoor A. Idiopathic interstitial pneumonias. In: Zander DS, Farver CF, editors. Pulmonary Pathology. 1st ed. Philalelphia: Elsevier; 2008. p.330-4.

13. Arbak P, Karacan Ö, İdilman R, Kaya A, Savaş I, Numanoğlu N. İdiopatik Pulmoner Fibrozis (12 Olgu Nedeni ile). Tüberküloz ve Toraks Dergisi 2000; 48: 57-62.
14. Johnston ID, Gomm SA, Kalra S, Woodcock AA, Evans CC, Hind CR. The managementof cryptogenic Fibrosin alveolitis in three regions of the United Kingdom. Eur Respir J 1983; 6: 891-3.

15. Tomasetti S, Cavazza A, Colby TV, Ryu JH, Nanni O, Scarpi E, et al. Transbronchial biopsy is useful in predicting UIP pattern. Respir Res 2012; 13: 96. [CrossRef]

16. Wasicek CA, Reichlin M, Montes M, Raghu G. Polymyositis and interstitial lung disease in apatient with anti Jo1 prototype. Am J Med 1984; 76: 538-44. [CrossRef]

17. Richeldi L, Davies HR, Ferrara G, Franco F. Corticosteroids for idiopathic pulmonary fibrosis. Cochrane Database Syst Rev 2003; 3: CD002880. [CrossRef]

18. Hubbard R, Johnson I, Britton J. Survival in patients with crytogenic fibrosing alveolitis: populatin-based cohort study. Chest 1998: 113: 396-400. [CrossRef]

19. Douglas W, Ryu J, Schoroeder DR. Idiopathic pulmonary fibrosis. Impact of oxygen and colchine, prednisone or no therapy on survival. Am J Respir Crit Care Med 2000; 161: 1172-8. [CrossRef]

20. King TE, Tooze JA, Schwarz MI, Brown KR, Cherniack RM. Predicting survival in idiopathic pulmonary fibrosis : scoring system and survival model. Am J Respir Crit Care Med 2001; 164: 1171-81. [CrossRef]

21. Idiopathic Pulmonary Fibrosis Clinical Research Network, Raghu G, Anstrom KJ, King TE Jr, Lasky JA, Martinez FJ. Prednisone, azathioprine, and N-acetylcysteine for pulmonary fibrosis. N Engl J Med 2012; 366: 1968-77. [CrossRef]

22. Disease-spesific approaches in pulmonary rehabilitation in; American Association of Cardiovascular and pulmonary rehabilition's (AACVPR's) Guidelines for Pulmonary rehabilitation Programs, 3rd ed 2004; 73-4.

23. Coşkun F. İdyopatik Pulmoner Fibrozis güncel tanı ve tedavi yaklaşımları. In: Fonksiyonel Değerlendirme. Kartaloğlu Z, Okutan O, editors. İstanbul 2013; 107-11.

24. Mogulkoç N, Brutsche MH, Bishop PW, Greaves SM, Horrocks AW, Egan $\mathrm{JJ}$; Greater Manchester Pulmonary Fibrosis Consortium. Pulmonary fuction in idiopathic pulmonary fibrosis and referal lung transplantation. Am J Respir Crit Care Med 2001; 164: 103-8. [CrossRef]

25. Meltzer EB, Noble PW. Idiopathic pulmonary fibrosis. Orphanet J Rare Dis 2008; 3: 8. [CrossRef]

26. O'Beirne S, Counihan IP, Keane MP. Intertitial lung disease and lung transplantation. Semin Respir Care Med 2010; 31: 139-46. [CrossRef]

27. Sulica R, Teirstein A, Padilla ML. Lung transplantation in intertitial lung disease. Curr Opin Pulm Med 2001; 7: 314-22. [CrossRef]

28. Okamoto T, Ichiyasu H, Ichikado K, Muranaka H, Sato K, Okamoto S, et al. Clinical analysis of the acute exacerbation in patients with idiopathic pulmonary fibrosis. Nihon Kokyuki Zasshi 2006; 44: 359-67.

29. Orens JB, Estenne M, Arcasoy S, Conte JV, Corris P, Egan JJ, et al. International guidelines fort he selection of lung transplant candidates: 2006 update - a concensus report from the pulmonary Scientific Council of the International Society of Heart and Lung Transplantation. J Heart Lung Transplant 2006; 25: 745-55. [CrossRef] 